\title{
Persistent, mobile and toxic substances in the environment: a spotlight on current research and regulatory activities
}

\author{
Heinz Rüdel ${ }^{1 *}$ (D) Wolfgang Körner ${ }^{2}$, Thomas Letzel ${ }^{3}$, Michael Neumann ${ }^{4}$, Karsten Nödler ${ }^{5}$ \\ and Thorsten Reemtsma ${ }^{6,7}$
}

\begin{abstract}
Certain persistent and polar substances may pose a hazard to drinking water resources. To foster the knowledge exchange in this field the Working Group Environmental Monitoring of the German Chemical Society (GDCh) Division Environmental Chemistry and Ecotoxicology discussed at their meeting in December 2018 the significance and relevance of persistent, mobile and toxic chemicals (PMT substances) in the environment. Five oral contributions highlighted not only various aspects such as the identification of potential PMT substances based on certain properties and their possible regulation under the European REACH regulation, but also current developments in the analysis of PMT substances and results from environmental monitoring. The data presented prove that many persistent and mobile substances can be detected in surface waters. Once detected, it can be complex and costly to identify sources and reduce inputs, as a case study on 1,4-dioxane in Bavarian surface waters shows. The same applies to the removal of polar substances from raw water for drinking water production. Today, scientific advances in analytical methods make it easier to identify and quantify even very polar substances in water samples. In addition to the targeted analysis of critical chemicals, non-target screening is playing an increasingly important role. This opens up the possibility of detecting substances in water samples that have not previously been investigated in routine monitoring and testing their relevance for humans and the environment. However, the list of potentially occurring PM substances that have not yet been investigated is still very long. Further methodological improvements seem necessary here. In view of the evidence for the presence of PMT substances in the environment (e.g., trifluoroacetic acid and 1,4-dioxane) and the potential risks for drinking water abstraction, it seems important under consideration of the precautionary principle to identify and prioritise relevant REACH-registered substances. The assessment should be based on the intrinsic properties and the emission potential of the compounds. The implementation of a detailed proposal made at European level to regulate PMT and very persistent and very mobile (VPvM) substances in the context of REACH would ensure that chemicals identified as being substances of very high concern according to the PMT and vPvM criteria are subject to authorisation in future.
\end{abstract}

Keywords: Persistence, Mobility, Toxicity, Water resources, Drinking water, Water production, Risk assessment, REACH regulation, Polar compounds, Non-target analysis

\footnotetext{
*Correspondence: heinz.ruedel@ime.fraunhofer.de

${ }^{1}$ Fraunhofer Institute for Molecular Biology and Applied Ecology

(Fraunhofer IME), Auf dem Aberg 1, 57392 Schmallenberg, Germany

Full list of author information is available at the end of the article
}

\begin{abstract}
Background
Substances with a specific combination of intrinsic substance properties might pose a hazard to drinking water resources. The combination of the two intrinsic substance properties persistence $(\mathrm{P})$ and mobility $(\mathrm{M})$ increases the probability for PM substances to pass natural barriers
\end{abstract}


like river banks and artificial barriers in water treatment facilities. Especially critical are substances that have toxic properties, too (PMT substances). Consequently, a contamination potentially becomes irreparable. In addition, substantial analytical challenges exist related to the detection and quantification of mobile (polar) substances in water samples during routine monitoring.

The Working Group Environmental Monitoring of the German Chemical Society (GDCh) Division Environmental Chemistry and Ecotoxicology discussed at their meeting in December 2018 the significance of persistent, mobile and toxic chemicals (PMT substances) in the environment. To gather information on the current knowledge on PMT substances experts were invited to present results from analytical research, environmental monitoring and regulation. Five oral contributions highlighted various aspects spanning from chemical risk assessment to analytical approaches regarding the detection of PMT substances.

\section{PMT and vPvM substances under REACH (M. Neumann, UBA)}

The EU REACH Regulation (EC) No. 1907/2006 is in force since 2007. REACH intends to ensure a high level of protection for human and environment health. Under $\mathrm{REACH}$, industry must demonstrate in their registration dossiers the safe use of substances over their entire life cycle. This includes to take into account the precautionary principle and to substitute substances of very high concern (SVHCs) and critical uses of chemicals. To date, approx. 22,400 substances have been registered under REACH by over 14,800 enterprises. In contrast, authorities have to date identified 197 substances as SVHCs of which 43 substances already entered the authorisation regime under REACH. By now, restrictions were implemented for 69 substances under REACH.

Ensuring that the drinking water sources are secure from any threats caused by chemicals is of the utmost importance. The EU Drinking Water Directive (98/83/ EC) and the EU Groundwater Directive (2006/118/EC) explicitly demand protection against chemical contamination. In contrast, an increasing number of chemicals are detected in the aquatic environment. A literature review (25 studies from 2000 to 2018; [1]) showed that already 333 chemicals were detected in groundwater and/or drinking water. Of these 333 chemicals, 142 (43\%) corresponded to substances that were registered under REACH (as of May 2017) of which 32 were also used as pharmaceuticals and five were also used as pesticides. The proportion of substances registered under REACH is even higher (53\%) if only those substances detected above $0.1 \mu \mathrm{g} \mathrm{L}^{-1}$ are considered. This shows that substances registered under $\mathrm{REACH}$ already today can pose a significant risk to drinking water quality.

A chemical substance emitted into the environment poses a threat to the drinking water resources, if it is transported from the point of emission through soil layers, river banks, aquifers, and other natural or even artificial barriers. The time scales for this transport can vary from a few days in the case of surface water sources, to 1 or 2 weeks for river bank filtration, or few years for remote groundwater extraction wells. Important factors are the scale of environmental emissions, and whether the substance, or its transformation products, are sufficiently persistent in the environment and enough mobile in the aquatic environment. The German Environment Agency (UBA) proposes to name such substances in the regulatory context of $\mathrm{REACH}$ persistent, mobile and toxic (PMT) substances or very persistent and very mobile (vPvM) substances [2-5].

The same intrinsic substance properties that lead to persistence in the environment and mobility in the aquatic environment might lead to a breakthrough in drinking water treatment facilities. They may not be removed by filters or by technical degradation procedures. Persistent and mobile substances can circulate in the water cycle and cause irreparable contamination. Therefore, it seems no sustainable solution to rely on retrospective and costly advanced water treatment technology to protect or remediate drinking water, particularly because even costly treatments are not completely effective in removing persistent and mobile substances.

A substantial analytical challenge exists related to the detection and quantification of mobile substance in water samples. Conventional methods using gas chromatography (GC) and reversed phase liquid chromatography (RPLC) are not able to detect and quantify the most mobile substances, such as those that are very polar, ionisable or ionic, resulting in high water solubility and low $n$-octanol-water partition coefficients $\left(K_{\mathrm{OW}}\right)$, or low $\mathrm{pH}$-dependant $n$-octanol-water distribution coefficients $\left(D_{\text {OW }}\right)$. This has recently been described as the analytical and monitoring gap [6], and is illustrated in the third contribution (see "Protection of water resources from traces of mobile substances" section).

The hazard posed by persistent chemicals that are mobile in the aquatic environment has been well known since decades. REACH currently lacks criteria for intrinsic substance properties that indicate a potential drinking water contaminant. Consequently, there is a regulatory gap between the requirements of the drinking water directive and REACH to fulfil the precautionary protection of the drinking water resources. Therefore, it was deemed necessary to scientifically and technically develop PMT/vPvM criteria under REACH. 
The German Environment Agency (UBA) since 2010 has funded research projects and since 2017 has performed two written consultations and several workshops. Neumann and Schliebner [5] present the result of this scientific and technical development of the PMT/vPvM criteria under REACH (refer to Fig. 1 for a scheme of the assessment procedure).

The persistence criterion $(\mathrm{P})$ and very persistent criterion $(\mathrm{vP})$ are taken directly from Annex XIII of REACH [7]. The main advantage is that it is consistent with existing regulatory definitions of $\mathrm{P}$ and $\mathrm{vP}$. This means that no additional workload is caused for registrants by the $\mathrm{PMT} / \mathrm{vPvM}$ assessment since an assessment of $\mathrm{P}$ and $\mathrm{vP}$ within the $\mathrm{PBT} / \mathrm{vPvB}$ assessment has to be performed for any registration above $10 \mathrm{t} \mathrm{a}^{-1}$.

The indication (screening) criterion for mobility is that the lowest $\log D_{\mathrm{OW}}$ over the $\mathrm{pH}$ range of $4-9$ is less than 4.5. Again, the main reasons are the compatibility to the screening for $\mathrm{B}$ and $\mathrm{vB}$ properties and the reduction of the workload under REACH for registrants. For neutral and non-ionisable substances over a specified $\mathrm{pH}$ range the $D_{\text {Ow }}$ has the same value as the $K_{\text {OW }}$.

The assessment criterion for the mobility is the lowest organic carbon-water partition coefficient $\left(\log K_{\mathrm{OC}}\right)$ over the $\mathrm{pH}$ range of 4-9: if the $\log K_{\mathrm{OC}}$ is less than $4.0 \mathrm{a}$ substance is assessed as mobile (M) and if the $\log K_{\mathrm{OC}}$ is

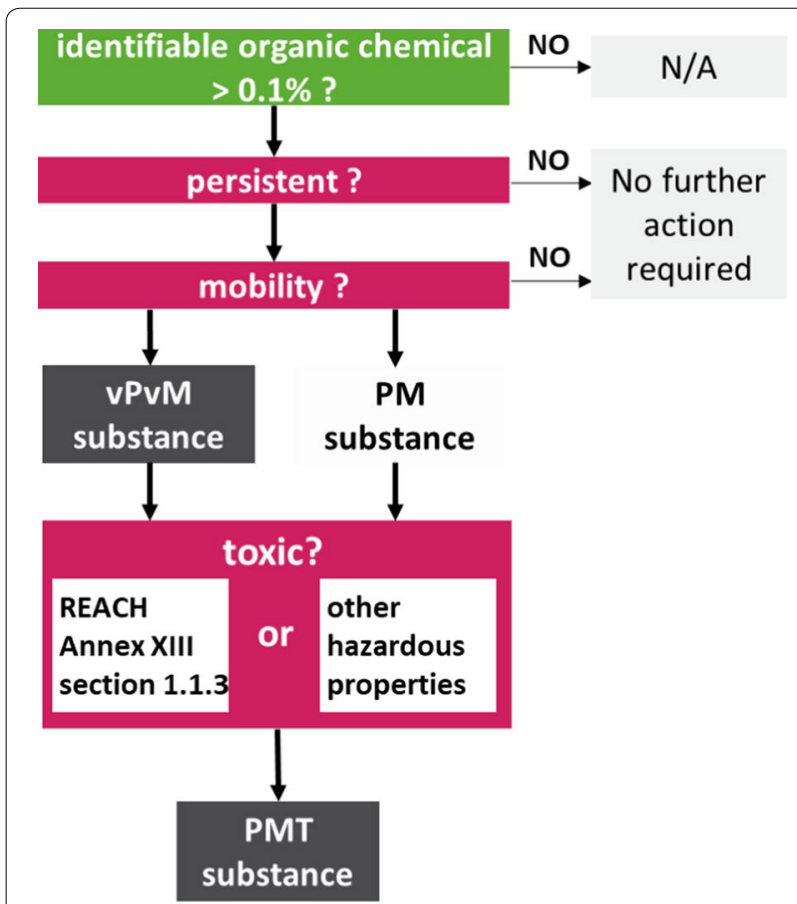

Fig. 1 Overview of the assessment procedure for identifying PMT/ vPVM substances registered under REACH [5]. For definitions refer to the text. N/A, not applicable less than 3.0 as very mobile (vM). The intrinsic substance property of mobility in the aquatic environment is on its own insufficient to imply a hazard due to enrichment in the source of drinking water [5]; rather, substances that are persistent and mobile are potential SVHCs. REACH and European Chemicals Agency's (ECHA) guidance documents point to the use of $K_{\mathrm{OC}}$ as the central intrinsic substance property to describe mobility (e.g., [8]). Water solubility is considered not to be a suitable property to set a threshold for the assessment of mobility. The principal reasons are difficulties when assessing ionic and ionisable substances, in which water solubility is dependent on counter ions [1]. The cut-off value of $\log K_{\mathrm{OC}} 3.0$ for $\mathrm{vM}$ is supported by scientific literature to be protective of groundwater and is currently utilised by the Groundwater Watch List coordinated by the EU Common Implementation Strategy Working Group Groundwater for identifying potential groundwater contaminants $[9,10]$. In addition, the cut-off value of $\log K_{\mathrm{OC}} 4.0$ for $\mathrm{M}$ is scientifically justified for the protection against bank filtration breakthrough [5].

The criteria for toxicity $(\mathrm{T})$ are mainly already set out in Annex XIII, 1.1.3 of REACH for the PBT/vPvB assessment [7]. Beyond these, there might be cases, where it is necessary to identify persistent and mobile substances with other hazardous properties posing a risk to human health and the environment. These additional toxicity (T) criteria are: classification as carcinogenic (category 2), germ cell mutagenic (category 2), or for effects on or via lactation according to Regulation EC No 1272/2008 [11]; the Derived-No-Adverse-Effect-Level (DNEL) is $\leq 9 \mu \mathrm{g} \mathrm{kg}^{-1} \mathrm{day}^{-1}$ (oral, long term, general population); or the substance acts as an endocrine disruptor in humans and/or wildlife species according to the WHO/ IPCS definition of an endocrine disruptor.

The evaluation approach proposed by UBA consists of two steps [5]. In the first step, the identification of PMT and $\mathrm{vPvM}$ substances is done by comparing the intrinsic substance properties with the PMT/vPvM criteria. The second step, the emission characterisation, includes recommendations for risk management measures (RMM) or the use of safe alternatives to minimise emissions and to protect the drinking water resources. Analogously to other hazardous substances under $\mathrm{REACH}$, regulatory measures for PMT/vPvM substances may only need to be considered by authorities, if registrants and downstream users do not put the necessary RMM into place.

The two most relevant regulatory instruments of authorities under $\mathrm{REACH}$ are the authorisation regime and the restriction. A restriction limits or prohibits the use of a substance if this would pose an unacceptable risk to human health or the environment. Under $\mathrm{REACH}$ such risks are identified by the Risk Assessment 
Committee (RAC) of the ECHA. In principle, the use of a substance is allowed, unless there is a restriction for certain (or all) uses.

An authorisation means that it is permitted and approved to use a substance in a certain way. In the authorisation regime the use of a substance is prohibited, unless there is an approval for a specific use. Within $\mathrm{REACH}$ a substance to be included into the authorisation regime must first be identified as an SVHC. According to REACH Article 57 (f) [7], this would be the case if for a PMT/vPvM substance the equivalent level of concern as for $\mathrm{PBT} / \mathrm{vPvB}$ substances were demonstrated. Under $\mathrm{REACH}$ this decision is to be taken on the basis of the intrinsic substance properties by the Member States Committee (MSC). The substance is then placed on the Candidate List. If the substance is finally included in Annex XIV of the REACH regulation, its use is prohibited and subject to approval.

In an ongoing research project on the behalf of UBA the PMT/vPvM criteria were applied to all substances registered under REACH (as of May 2017) [1]. To date, approximately $260 \mathrm{PMT} / \mathrm{vPvM}$ substances have been identified within this research project. The substance list will be prioritised according to the type of use and the resulting risk of emission.

\section{Relevance of organic micropollutants for drinking water supply (K. Nödler, TZW)}

A recent example demonstrates the relevance of organic micropollutants for drinking water supply: In 2016, concentrations of more than $20 \mu \mathrm{g} \mathrm{L}{ }^{-1}$ trifluoroacetate (TFA) were detected in the bank filtrate of the river Neckar (Germany) [12]. This caused nationwide attention and led to further analyses of the occurrence of TFA in surface, ground and drinking water. It was shown that the Rhine is also influenced by the identified point source at the Neckar and that this affects drinking water supply more than $300 \mathrm{~km}$ downstream. TFA is the anion of trifluoroacetic acid which, according to the REACH database, is marketed in Europe with a tonnage of 1000-10,000 $\mathrm{t} \mathrm{a}^{-1}$ (e.g., as raw material or solvent). Natural sources may also exist but only seem to be relevant in the marine environment. In contrast, TFA was identified as a transformation product of a large variety of substances (propellants and refrigerants, pesticides, pharmaceuticals). In the substance assessment of the herbicide flurtamone, TFA was identified as a so-called non-relevant metabolite (German health orientation value $1 \mu \mathrm{g} \mathrm{L}{ }^{-1}$ until the end of 2016, $3 \mu \mathrm{g} \mathrm{L}^{-1}$ since January 2017). On the basis of the available data, TFA can be assessed as persistent and highly mobile in the water cycle and its detection in drinking water is not surprising at all. However, TFA is only one example of substances that can interfere with drinking water supply.

In order to protect the drinking water resources, proactive (i.e., emission-related) protection is necessary, so that it becomes possible to identify critical substances at an early stage-ideally before their use or during the approval or registration process. However, this is a huge challenge against the backdrop of the large number of registered and pre-registered compounds (see section "PMT and vPvM substances under REACH (M. Neumann, UBA)"). Therefore, a risk-based prioritisation of critical substances relevant for water supply was carried out at TZW. On the basis of intrinsic properties, entry pathways/scenarios, and consumption volumes of the substances, the probability of occurrence in drinking water and the associated risk were evaluated.

Aim of the project, funded by DVGW (German Technical and Scientific Association for Gas and Water) with the short title Hot-Target-approach, was to identify drinking water-relevant chemicals with highest priority for drinking water supply out of a substance pool of about 10,400 environmentally relevant substances from various databases. During the evaluation of the substance databases synergies with other projects were built up. Among others, the STOFF-IDENT database (HS WeihenstephanTriesdorf, LfU Bavaria, TU Munich, and Zweckverband Landeswasserversorgung) [13] was used and information on REACH substances, drug and plant protection products (both active substances and transformation products) as well as and biocides was compiled. In addition, information from water suppliers was taken into account and scientific literature (i.e., occurrence studies) evaluated. One difficulty with the intersection of the data sources was that the substance data sets partly referred to different substance forms (e.g., free acid vs. anion/cation or salt). The InChIKey (International Chemical Identifier) proved to be the most suitable identification feature for the comparison and harmonisation of the data. As a general recommendation, InChIKeys should be systematically added in chemical databases as unique substance identifiers in order to guarantee that in the future search and retrieval of data from existing databases will be univocally linked to the chemical structure of a compound.

In the first step of the risk-based prioritisation, worst case criteria were used for the screening of substances from the Hot-Target basic database without resorting to experimental data and production/consumption volumes. Thus, parameters for mobility and technical removability of substances during drinking water treatment as well as the biological half-lives of substances were estimated using different QSARs (ACD/Percepta (ACD/Labs) and ChemAxon for the calculation of log $D_{\text {Ow; }}$ US EPA's BIOWIN for biodegradation assessment) 
and other theoretical approaches (e.g., read across). In addition, during the first screening, the hazard potentials of the substances were assessed on the basis of any conspicuous structural features. During the subsequent refinement, a detailed assessment of the Hot-Targetcandidates (i.e., drinking water-relevant substances that cannot be removed by ozonation and/or activated carbon treatment and from which potential hazards emanate) was carried out on the basis of experimental data (if available). Screening and refinement procedures are explained in a more detailed manner in the following sections.

\section{Screening criteria}

To assess the mobility of substances in the subsurface, the criteria of previous works were examined: Provided that there is no valid experimental $K_{\mathrm{OC}}$ data, the sorption estimation is mostly carried out via the $K_{\mathrm{OW}}$ (or $K_{\mathrm{OW}} / K_{\mathrm{OC}}$ relations). However, the $K_{\mathrm{OW}}$ is not always sufficient for an evaluation of sorption. For example, for ionic or ionisable substances, the mobility of organic acids may be underestimated, whereas the mobility of organic bases that can be retained by cation exchange processes may be overestimated for raw water typically within a $\mathrm{pH}$ range of 6-9. A statistical evaluation from 2010 showed that about half of the substances registered under the REACH regulation are ionisable compounds [14].

To assess the drinking water relevance of organic compounds, the potential removal by sorption (e.g., during river bank passage) was taken into account. Therefore, the speciation of the compound has to be considered: The selected criteria for drinking water relevant compounds were $\log D_{\mathrm{OW}}<4.5$ and $<60 \%$ of the cationic species of the compound (both to be evaluated at $\mathrm{pH} 8$ ) to consider removal by hydrophobic interactions and cation exchange, respectively. Further criteria are the particular consideration of small molecules (i.e., molecular mass of $\leq 200 \mathrm{Da}$ ) and of data on biological degradation (model based on US EPA's BIOWIN; https://www.epa.gov/tscascreening-tools/epi-suitetm-estimation-program-inter face). Volatility and water solubility, on the other hand, are not included in the evaluation.

In order to assess the toxicological relevance, the Hot-Target-approach initially uses-if available-existing assessments of the substances to be prioritised (e.g., drinking water guideline values, health orientation values, classifications as carcinogenic, mutagenic and reproduction-toxic (CMR) substances, data from international lists of carcinogenic substances or from available REACH assessments). A software-supported search for conspicuous features in the chemical structures was carried out for the screening of hitherto unevaluated substances (with regard to possible genotoxic and non-genotoxic carcinogenicity) with the Toxtree application (http:// toxtree.sourceforge.net/).

For the evaluation of the potential removal of substances by ozonation, an automated database query was performed for structural characteristics with known favourable reaction kinetics (e.g., molecules with $\mathrm{C}-\mathrm{C}$ double bonds or aniline- $\mathrm{N}$ are considered as reactive [15]). The evaluation of potential removability of substances by activated carbon treatment is based on hydrophobicity. The cut-off value (i.e., removable: compounds

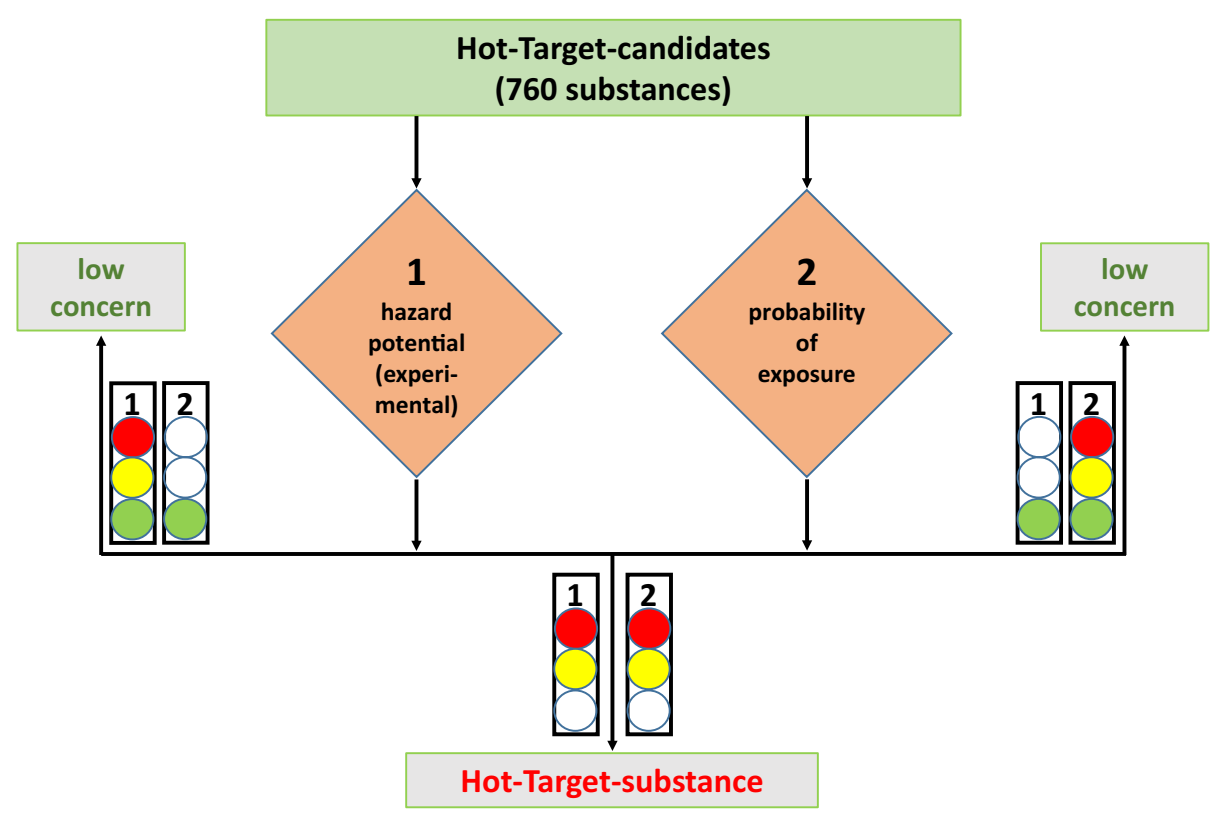

Fig. 2 Scheme for the evaluation of the substances identified as Hot-Target-candidates (modified from [17]) 
with a $\log D_{\mathrm{OW}} \geq 2.5$ ) was derived by meta-analysis of inhouse small-scale filter tests [16].

\section{Refined procedure}

By applying the selected screening criteria, it was possible to identify 760 substances as potentially drinking water relevant priority substances, for which the usual technical risk management measures are unlikely to be successful. These Hot-Target-candidates were subjected to a substance-per-substance evaluation in a refined procedure (Fig. 2). The hazard potential of each substance was evaluated on the basis of experimental data (if available). To assess the probability of exposure, entry pathways/scenarios and consumption volumes as well as available experimental data on mobility and (bio-)degradation were taken into account. Green light on any criterion (i.e., very low probability of exposure or very low hazard potential) indicates very low risk. The respective compound is not high priority and, thus, considered as false-positive result of the screening procedure. In case of lacking or inconsistent experimental data, the traffic light was set to yellow (i.e., medium exposure/hazard potential).

Nine substances that are critical with regard to both criteria (i.e., red light twice: high concern at hazard and exposure level) were classified as Hot-Target-substances with priority A: 1,4-dioxane, trichloroethene, trichloromethane, 2,4-dinitrophenol, tris(2-chloroethyl)phosphate (TCEP), 1,2-dichloropropane, trichloroacetic acid, 1,2-dichloroethane, and 1,2-dimethoxyethane (monoglyme). Further 80 chemicals were identified as Hot-Target-substances with priority B (i.e., no green light on any level: no clear relief at hazard and/or exposure level).

Several important aspects of the presented approach should be highlighted. First of all, the availability of robust experimental data is often insufficient for a proper assessment. Furthermore, as the precautionary principle needs to be considered, anthropogenic substances in drinking water are undesirable, even if there is no indication for toxicological concerns. Persistence alone is a major cause of concern and possible risks may be identified long time after the compounds' use [18]. Therefore, the use of persistent substances should be strictly limited to essential applications and the development of readily degradable substitutes has to be top priority. Furthermore, current assessments do usually not include the potential formation of persistent and mobile transformation products from precursor molecules. The presence of multiple primary (i.e., discharge of the compound itself) and secondary (i.e., from the degradation of precursor molecules) sources of such compounds in drinking water catchments is an upcoming challenge for the drinking water sector and regulatory frameworks, as the identification of the main source(s) may be complex and the implementation of efficient mitigation strategies is delayed [19].

In general, the availability of technical solutions for the elimination of PM substances during drinking water purification must not replace any strategies for resource protection, as the formation of harmful by-products during, e.g., ozonation is a potential threat [20]. This statement is very well in line with requirements of article 7(3) of the European Water Framework Directive, which states that Member States shall ensure the necessary protection for the bodies of water identified with the aim of avoiding deterioration in their quality in order to reduce the level of purification treatment required in the production of drinking water [21].

The report on the Hot-Target-approach is available via the DVGW [17].

\section{Protection of water resources from traces of mobile substances (T. Reemtsma, UFZ)}

Some PM compounds have been known as surface water contaminants, e.g. pyrazole, TFA or 1,4-dioxane, but monitoring methods that enabled the detection of larger numbers of highly polar trace substances from water are not well developed (analytical gap) [6]. In addition to this analytical gap there is also a protection gap for PM substances: since they are very mobile in the aquatic environment and hardly degraded microbially, the barriers in partially closed water cycles are not effective and the concentrations of PM compounds are reduced by dilution only.

As part of the Water JPI initiative of the EU, the European project PROMOTE with partners from five

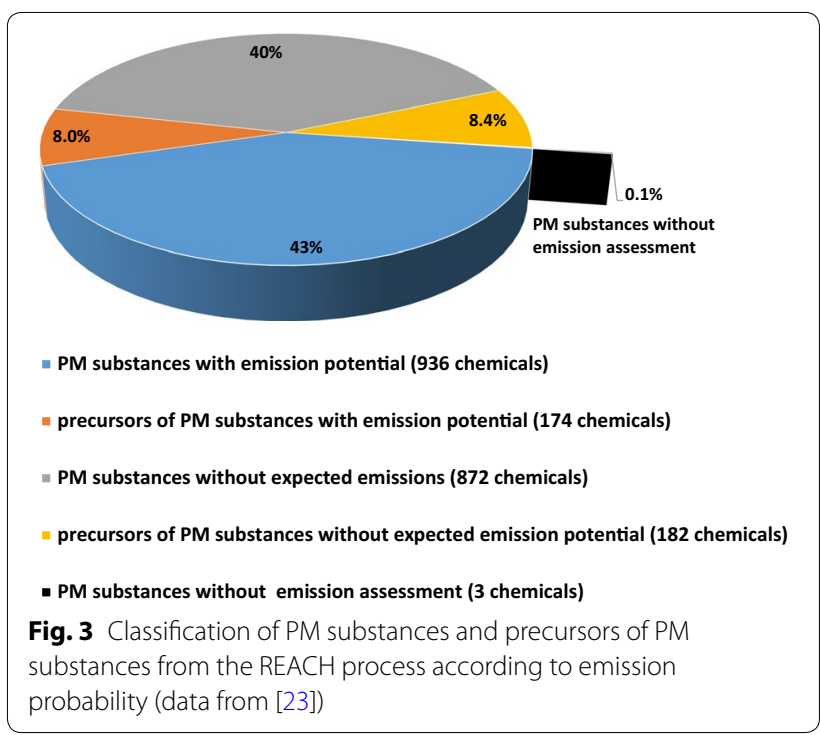


countries has pursued two approaches to reduce the knowledge gap on PM compounds. Firstly, 14,000 substances registered according to the $\mathrm{REACH}$ regulation were prioritised with regard to their PM characteristics starting from the registration data [22]. About 2200 $\mathrm{REACH}$-registered substances were evaluated as persistent and mobile because of their properties or because they form transformation products with such properties. Subsequently, the emission potential for these substances was also estimated [23] based on the marketed tonnage in Europe as well as on their use characteristics (release into the environment vs. use in closed systems). The application of this model led to a list of about 1100 PM substances for which a release into the environment was considered relevant (Fig. 3) [23]. Compounds on this list may be included into future suspect screening activities or selected for the development of targeted methods for PM compounds.

Although the list of 1100 PM compounds is more than an order of magnitude larger than the list of Hot-Targetsubstances of Nödler et al. [17] and section "Relevance of organic micropollutants for drinking water supply (K. Nödler, TZW)" above, not all compounds from that list are also included here. This is primarily due to the fact that the PM list focusses on REACH chemicals, while the Hot-Target list started with a more diverse spectrum of contaminants, including also pharmaceuticals and pesticides.

Secondly, three project partners have improved analytical methods based on liquid chromatography-mass spectrometry (LC-MS) methods for highly polar substances. They used hydrophilic interaction liquid chromatography (HILIC; [24, 25]), mixed-mode liquid chromatography (MMLC; [26]) and supercritical fluid chromatography (SFC; [27]). In this way they could significantly extend LC-MS methods towards more polar contaminants. The methods were used to determine the occurrence, frequency of detection and semi-quantitative concentrations of $64 \mathrm{PM}$ substances in water samples (mostly surface water, groundwater, bank filtrate) from Spain, France, the Netherlands and Germany [27]. $33 \%$ of the target analytes were present in at least $50 \%$ of the analysed water samples. These included some previously known polar trace substances such as melamine, tris(1,3-dichloro-2-propyl)phosphate), acesulfame and epsilon-caprolactam. The predominant number of positive findings, however, concerned industrial chemicals that had not previously been reported to occur in environmental water samples, such as 1,3-diphenylguanidine, p-toluenesulfonic acid, trifluoromethane sulfonic acid, 2-acrylamino-2-methylpropanesulfonic acid, xylenesulfonic acid and cyanoguanidine. The results revealed that PM compounds occurred in the water cycle in concentrations ranging from the low $n g \mathrm{~L}^{-1}$ up to $\mu \mathrm{g} \mathrm{L}^{-1}$ range [27].

With regard to drinking water preparation, some of the detected organic PM substances are neither removed by "conventional" processes nor by advanced treatment with activated carbon or ozone. This group comprises, e.g. trifluoromethane sulfonic acid, xylene sulfonic acid, cyanoguanidine, 2-acrylamino-2-methylpropanesulfonic acid, melamine, and acesulfame. These results indicate that current technical and environmental barriers are not sufficient to safely eliminate all PM chemicals. This suggests that, indeed, a protection gap exists for drinking water. This gap should be known more precisely and measures need to be developed to improve the protection of our water resources.

Since 2019, the investigations on the occurrence of PM substances in the water cycle and on possibilities of their removal are being continued at a national level in a project funded by the German Federal Ministry for Education and Research (BMBF) also coordinated by UFZ (Project PROTECT; http://www.ufz.de/protect).

\section{Identification and detection of very polar components in aqueous environmental samples ( $T$. Letzel, TU Munich)}

Anthropogenic organic trace substances reach the environment via different input paths where diffuse as well as point sources play a role. Sewage treatment plants (STPs) are the most important point sources for these substances [28]. The usual monitoring spectrum for the investigation of STP effluents only covers a limited number of substances (target analysis). Non-target screening approaches now offer the possibility to identify further relevant substances. Both procedures together open up the possibility of determining a comprehensive spectrum of substances occurring in water bodies.

The organic trace substances can have very different polarities, which thus require different analytical methods. The serial RPLC-HILIC coupling has proven to be optimal for the simultaneous analysis of very polar, polar and non-polar substances [29]. Studies were carried out, for example, in a river before and after the introduction of discharges of an STP as well as directly in the effluent. For this purpose, 24-h composite samples were used. Initially, the samples were concentrated on a C18-HILIC solid phase. The analyses were then carried out using RPLC-HILIC and atmospheric pressure interface-time of flight-MS coupling (API-ToF/MS). The HILIC method separates substances with $\log D_{\mathrm{OW}}<0$, the RPLC substances with $\log D_{\text {OW }}>0$.

In the meantime a large number of data on relevant substances have been compiled, which are also publicly available in the database STOFF-IDENT (https://www. 
lfu.bayern.de/stoffident/). This continuously updated database with so far more than 11,000 entries contains, e.g., REACH-registered chemicals, active substances of drugs, biocides and plant protection products as well as known transformation products of these compounds and other relevant substances potentially occurring in waters.

During the exemplary investigation of STP effluents and upstream/downstream sampling points using RPLCHILIC/ToF-MS, several hundred features (characterised by retention time and accurate MS data) were detected. These were then further characterised in a more complex workflow by using the FOR-IDENT platform (https ://water.for-ident.org) and the STOFF-IDENT database. This includes blank value correction as well as the assignment of suitable structures to the MS data and a filtering/ prioritisation of the data with regard to the $\log D_{\mathrm{OW}}$ value range. The selected features are then checked manually. The verification of the substances is done by comparison with available standards and by a tandem MS confirmation analysis. However, the assignment is not always possible, because isomers are not separated or several chemical structures may fit to one feature.

With this methodology, 54 suggestions could be made from 462 features (partly identified by matching MS data with databases of substances already tested). 32 of these substances were finally confirmed by measurements of available standards. Examples are $N, N^{\prime}$-ethylenedi(diacetamide), 2,2,6,6-tetramethyl-4-piperidone or melamine as industrial chemicals, gabapentin as a drug or adenine, which is a biogenic substance but also produced and used industrially (data not yet published). Polarity-enhanced chromatographic methods such as RPLC-HILIC/ToF-MS and SFC/ToF-MS close the gap for the analysis of very polar molecules and are expected to be increasingly used in environmental monitoring in the future. Further examples for detected proven vP substances are maleic acid, betaines (e.g., also contained in personal care products such as shower gels), metformin, tenofovir or taurine. As polar substances, 2-butylaminoethanol, piperidine or diisopropylamine were found. However, it was also possible to determine routinely many amino acids, which are to be regarded as substances occurring naturally in waters.

These investigations demonstrate that the now possible separation of very polar molecules by polarity-enhanced analytical separation techniques already opens up a deeper insight into the diversity of molecules occurring in waters. For further monitoring of new substances by a target screening, isotope-labelled internal standards are typically used and the quantitative results of different real samples are determined. In the short-to-medium term, this will form a sound basis for interpreting the relevance of (very) polar molecules in the aquatic environment.

\section{Case study: 1,4-dioxane in Bavarian water bodies- analysis, sources, emission reduction (W. Körner, LfU Bavaria)}

1,4-Dioxane is a persistent and mobile substance occurring in wastewater treatment effluents and the aquatic environment and clearly meets the PMT criteria [30]. The chemical is used as a solvent in numerous areas. UBA has set a human health-based guidance value for drinking water of $5 \mu \mathrm{g} \mathrm{L}^{-1}$ for lifelong intake [31]. In spring 2016, 1,4-dioxane was found in river bank filtrate near the mouth of a tributary to the river Danube during investigations for the $\mathrm{LfU}$ project Climate change and water supply in Bavaria (unpublished results). As a result, LfU developed a modified headspace method coupled to gas chromatography mass spectrometry (GC-MS) for the determination of 1,4-dioxane in water in summer 2016, which achieves a limit of determination of $0.2 \mu \mathrm{g}$ $\mathrm{L}^{-1}$, and since May 2017 even of $0.1 \mu \mathrm{g} \mathrm{L}^{-1}$. The method has been used for the determination of 1,4-dioxane in the Danube and its tributaries. Using this rapid method, four dischargers of 1,4-dioxane were identified at the tributary mentioned above. The two dischargers with the largest loads are manufacturers of polyester fibres, where 1,4-dioxane is formed in an acid-catalysed side reaction of ethylene glycol.

In February 2017, a mobile plant for the treatment of the complete dioxane-containing wastewater with catalytic oxidation with Fenton's reagent and UV irradiation in a batch process was installed at one of the two plants, which was replaced by a stationary plant in August 2018. The dioxane load has been demonstrably reduced by 95-98\% with both systems. The other polyester manufacturer also installed an additional mobile wastewater treatment plant in April 2017, but this was only sufficient for $30 \%$ of the dioxane-containing wastewater. In November 2018, a distillation plant for all dioxane-containing wastewater from the plant was commissioned at that site, and the dioxane-containing distillates are now subsequently incinerated. After a start-up phase, a reduction of the dioxane load by $90-98 \%$ is achieved.

As third dioxane source a paper mill was identified. Recently, the company identified an auxiliary substance which contained 1,4-dioxane. A dioxane-free replacement substance has successfully been introduced. Dioxane inputs were also caused by a plant producing chemical products for the textile industry. Technical hydrochloric acid, which is used to neutralise wastewater, was identified here as the dioxane source. The acid stemmed from three technical processes and contained about $2 \mathrm{~g} \mathrm{~L}^{-1}$ 1,4-dioxane. It was replaced by dioxanefree technical hydrochloric acid in 2017. Since then, dioxane emissions have decreased by over $90 \%$. 
With the measures already implemented at the four plants, a significant reduction of the dioxane mass flow was measured as early as mid-2018. Therefore, 1,4-dioxane concentrations of about $5 \mu \mathrm{g} \mathrm{L}^{-1}$, as observed in the dry winter of 2016/2017 near the river mouth, did not occur any longer, even in the extremely dry summer of 2018.

As a further important source of 1,4-dioxane at another tributary of the Danube, a company has been identified which manufactures different surfactant products and precursors, including those based on ethoxylate (unpublished results). Due to acid-catalysed side reactions of ethylene glycol and diethylene glycol these production processes also result in 1,4-dioxane. By August 2018, various measures, including the separation of wastewater containing dioxane and subsequent incineration, had reduced total dioxane emissions at this site by more than $50 \%$.

Bavaria-wide, from October 2016 to mid-2017, more than 40 surface water monitoring sites were analysed for 1,4-dioxane every 4 weeks. In 2018, this monitoring was continued with 19 measuring points and the drains of the four STPs to which the dischargers described above are connected. In 2019 and 2020, 1,4-dioxane monitoring is continued with 13 measuring points plus four STP effluents. It will be supplemented by a targeted search for sources at a tributary of the Danube where only temporarily high 1,4-dioxane concentrations occur. Moreover, an attempt will be made to trace the cause for irregular detection of 1,4-dioxane concentrations in the river Main upstream of the city of Bamberg, which is still unknown despite an extensive sampling campaign.

The experiences gained in Bavaria since 2016 reveal that regular and targeted monitoring can contribute decisively to identify emission sources for 1,4-dioxane in water bodies, to justify and demand emission-reducing measures, and to demonstrate and monitor the effectiveness of these measures.

\section{Conclusions}

Meanwhile many investigations prove that PM substances are detectable in surface waters. Once detected, it can be very costly to identify their sources and to reduce inputs, as the case study on 1,4-dioxane in Bavarian waters reveals. The same applies to the removal of critical polar substances from raw water for drinking water processing. However, the toxicity of many PM substances is still unclear $[1,30]$. This issue needs further consideration, especially in the case of PM substance findings close to drinking water production.

Today, advances of analytical methods make it easier to quantify even strongly polar substances in water samples.
In addition to the targeted analysis of critical chemicals, non-target screening is gaining an increasingly important role. This opens up the possibility of detecting substances in water samples that have not previously been covered in the routine monitoring, and to test their relevance for human health and the environment. However, the list of potentially occurring but not yet tested PM substances is still very long. Here, further methodological improvements seem necessary.

In view of the evidence for the occurrence of PMT substances in the environment (e.g., TFA and 1,4-dioxane) and the potential risks for drinking water production, it seems important in terms of the precautionary principle to identify and prioritise REACH-registered substances as relevant for environment monitoring due to the intrinsic substance characteristics $\mathrm{P}$ and $\mathrm{M}$ and their emission potential. The proposal made at the European level to regulate PMT and $\mathrm{vPvM}$ substances in the context of the REACH regulation would ensure that chemicals identified as of very high concern according to these criteria would be subject to an authorisation in future.

The current state of research on PMT substances will be presented in January 2020 at an international workshop co-organised by the NORMAN network in Leipzig (https://www.normandata.eu/?q=node/354). Members of the GDCh-Working Group Environmental Monitoring of the German Chemical Society will be supporting this meeting.

\section{Abbreviations}

API: atmospheric pressure interface; CMR: carcinogenic, mutagenic and reproduction-toxic; $D_{\text {ow: }}$ n-octanol-water distribution coefficient; DVGW: Deutscher Verein des Gas- und Wasserfaches e.V. (German Technical and Scientific

Association for Gas and Water); EU: European Union; GC: gas chromatography; GC-MS: gas chromatography-mass spectrometry; GDCh: Gesellschaft Deutscher Chemiker (German Chemical Society); HILIC: hydrophilic interaction liquid chromatography; InChIKey: International Chemical Identifier; $K_{\text {oc: }}$ soil organic carbon-water partition coefficient; $K_{\text {ow: }} n$-octanol-water partition coefficient; LfU Bavaria: Bavarian Environment Agency (Bayerisches Landesamt für Umwelt); MMLC: mixed-mode liquid chromatography; N/A: not applicable; NORMAN: Network of reference laboratories, research centres and related organisations for monitoring of emerging environmental substances; PM: persistent and mobile; PMT: persistent, mobile and toxic; REACH: Registration, Evaluation, Authorisation and Restriction of Chemicals (EU Regulation); RMM: risk management measures; RPLC: reversed phase liquid chromatography; SFC: supercritical fluid chromatography; STP: sewage treatment plant; SVHC: substance of very high concern; TFA: trifluoroacetate; ToF/MS: time of flightmass spectrometry; TU Munich: Technical University of Munich; TZW: DVGWTechnologiezentrum Wasser; UBA: Umweltbundesamt (German Environment Agency); UFZ: Helmholtz Centre for Environmental Research (Umweltforschungszentrum); UV: ultraviolet; $v$ PvM: very persistent and very mobile.

\section{Acknowledgements}

Regarding section PMT and VPVM substances under REACH (M. Neumann, UBA): This study was contracted for the Environmental Research of the Federal Ministry for the Environment, Nature Conservation, and Nuclear Safety in Germany, from 2016 to 2019 as project No. FKZ 3716674160 to H.P.H. Arp and S.E. Hale from NGI—Norwegian Geotechnical Institute under the title REACH: Improvement of guidance and methods for the identification and assessment of PMT/vPvM substances. 


\section{Authors' contributions}

HR initiated this contribution and conceived the conclusions. WK, TL, MN, KN and TR contributed specific sections (author names given in headings). All authors read and approved the final manuscript.

\section{Funding}

The preparation of this manuscript was not funded by third parties.

\section{Availability of data and materials}

Data are either original data from the authors' institutions and/or are from the references given.

\section{Ethics approval and consent to participate}

Not applicable.

\section{Consent for publication}

Not applicable.

\section{Competing interests}

All authors declare that they have no competing interests.

\section{Author details}

${ }^{1}$ Fraunhofer Institute for Molecular Biology and Applied Ecology (Fraunhofer IME), Auf dem Aberg 1, 57392 Schmallenberg, Germany. ${ }^{2}$ Unit Analysis of Organic Compounds, Bavarian Environment Agency (LfU), Bürgermeister-Ulrich-Strasse 160, 86179 Augsburg, Germany. ${ }^{3}$ Analytical Research Group, Chair of Urban Water Systems Engineering, Technical University of Munich, Am Coulombwall 3, 85748 Garching, Germany. ${ }^{4}$ German Environment Agency (Umweltbundesamt), Wörlitzer Platz 1, 06844 Dessau-Rosslau, Germany. ${ }^{5}$ TZW: DVGW-Technologiezentrum Wasser (German Water Centre), Karlsruher Straße 84, 76139 Karlsruhe, Germany. ${ }^{6}$ Department of Analytical Chemistry, Helmholtz Centre for Environmental Research-UFZ, Permoserstrasse 15, 04318 Leipzig, Germany. ${ }^{7}$ Institute for Analytical Chemistry, University of Leipzig, Linnéstrasse 3, 04103 Leipzig, Germany.

\section{Received: 17 September 2019 Accepted: 29 December 2019}

Published online: 18 January 2020

\section{References}

1. Arp HPH, Hale SE (2019) REACH: Improvement of guidance and methods for the identification and assessment of PM/PMT substances. UBA Texte 126/2019. Project number: FKZ 371667416 0. ISSN: 1862-4804. German Environmental Agency (UBA), Dessau-Rosslau, Germany. 129 p. https://www.umweltbundesamt.de/sites/default/files/medien/1410/ publikationen/2019-11-29_texte_126-2019_reach-pmt.pdf. Accessed 20 Dec 2019

2. Neumann M, Schwarz MA, Sättler D, Oltmanns J, Vierke L, Kalberlah F (2015) A proposal for a chemical assessment concept for the protection of raw water resources under REACH. Extended Abstract for the Oral presentation at the 25th annual meeting of the Society of Environmental Toxicology and Chemistry (SETAC Europe), 3-7 May 2015, Barcelona, Spain

3. Neumann M (2017) Proposal for criteria and an assessment concept for the identification of Persistent, Mobile and Toxic (PMT) substances to protect raw water for the production of drinking water under the EU regulation REACH [in German]. Zbl Geol Paläont Teil I 2017:91-101

4. Neumann M, Schliebner I (2017) Protecting the sources of our drinking water from mobile chemicals - a revised proposal for implementing criteria and an assessment procedure to identify Persistent, Mobile and Toxic (PMT) and very Persistent, very Mobile (vPvM) substances registered under REACH. German Environmental Agency, Dessau-Rosslau, Germany. ISSN: 2363-8273. 20 pages https://www.umweltbundesamt .de/sites/default/files/medien/1410/publikationen/171027_uba_pos_ pmt_substances_engl_2aufl_bf.pdf. Accessed 20 Dec 2019

5. Neumann M, Schliebner I (2019) Protecting the sources of our drinking water: The criteria for identifying Persistent, Mobile, and Toxic (PMT) substances and very Persistent, and very Mobile (vPvM) substances under the EU chemical legislation REACH. UBA Texte 127/2019. ISSN: 1862-4804. German Environmental Agency (UBA), Dessau-Rosslau,
Germany. https://www.umweltbundesamt.de/sites/default/files/medie n/1410/publikationen/2019-11-29_texte_127-2019_protecting-sourc es-drinking-water-pmt.pdf. Accessed 20 Dec 2019

6. Reemtsma T, Berger U, Arp HPH, Gallard H, Knepper TP, Neumann M, Quintana JB, de Voogt P (2016) Mind the Gap: persistent and mobile organic compounds-water contaminants that slip through. Environ Sci Technol 50:10308-10315

7. European Parliament and Council (2006) Regulation (EC) No 1907/2006 of the European Parliament and of the Council of 18 December 2006 concerning the Registration, Evaluation, Authorisation and Restriction of Chemicals (REACH), establishing a European Chemicals Agency, amending Directive 1999/45/EC and repealing Council Regulation (EEC) No 793/93 and Commission Regulation (EC) No 1488/94 as well as Council Directive 76/769/EEC and Commission Directives 91/155/ EEC, 93/67/EEC, 93/105/EC and 2000/21/EC. Official Journal L 396, 30.12.2006, pp 1-849

8. ECHA (2017) Guidance on Information Requirements and Chemical Safety Assessment Chapter R.7a: Endpoint specific guidance. Version 6.0, July 2017. ISBN 978-92-9495-970-6. European Chemicals Agency (ECHA), Helsinki, Finland https://echa.europa.eu/documents/10162 /13632/information_requirements_r7a_en.pdf. Accessed 20 Dec 2019

9. Kozel R, Wolter R (2018) Voluntary Groundwater Watch List Concept \& Methodology. Based on final draft 12.3, endorsed by CIS Working Group-Groundwater (WG GW). Common Implementation Strategy for the Water Framework Directive and Floods Directive, p 38. https:// circabc.europa.eu/d/d/workspace/SpacesStore/63f48ec1-6da8-4b5baed7-71e018324d71/Groundwater\%20watch\%20list.pdf. Accessed 20 Dec 2019

10. Lapworth DJ, Lopez B, Laabs V, Kozel R, Wolter R, Ward R, Vargas Amelin E, Besien T, Claessens J, Delloye F, Ferretti E, Grath J (2019) Developing a groundwater watch list for substances of emerging concern: a European perspective. Environ Res Lett 14:035004. https://doi. org/10.1088/1748-9326/aaf4d7

11. European Parliament and Council (2008) Regulation (EC) No 1272/2008 of the European Parliament and of the Council of 16 December 2008 on classification, labelling and packaging of substances and mixtures, amending and repealing Directives 67/548/EEC and 1999/45/EC, and amending Regulation (EC) No 1907/2006. Official Journal L 353, 31.12.2008, p. 1-1355

12. Scheurer M, Nödler K, Freeling F, Janda J, Happel O, Riegel M, Müller U, Storck FR, Fleig M, Lange FT, Brunsch A, Brauch H-J (2017) Small, mobile, persistent: trifluoroacetate in the water cycle-overlooked sources, pathways, and consequences for drinking water supply. Water Res 126:460-471

13. Grosse S, Letzel T (2016) User Manual for STOFF-IDENT Database (4.2) 33 p. https://www.Ifu.bayern.de/stoffident/stoffident-static-content/ html/download/manual.pdf (accessed: December 20, 2019)

14. Franco A, Ferranti A, Davidsen C, Trapp S (2010) An unexpected challenge: ionizable compounds in the REACH chemical space. Int J Life Cycle Assess 15:321-325

15. von Gunten U (2003) Ozonation of drinking water: Part I. Oxidation kinetics and product formation. Water Res 37:1443-1467

16. Happel O, Graf C, Mertineit S, Brauch H-J (2009) Aktivkohle-Kleinfiltertest zur Bewertung der Entfernbarkeit organischer Spurenstoffe in der Trinkwasseraufbereitung, Beiträge zur Jahrestagung der Wasserchemischen Gesellschaft. p. 202-206

17. Nödler K, Happel O, Scheurer M, Storck FR, Brauch H-J (2018) Selektion von für die Wasserversorgung relevanten prioritären Stoffen und Erarbeitung einer Stoffliste. Abschlussbericht W 201515. DVGW, 201811. https://www.dvgw.de/leistungen/forschung/forschungsberichte/ dvgw-forschungsbericht-w-201515. Accessed 20 Dec 2019

18. Cousins IT, Ng CA, Wang Z, Scheringer M (2019) Why is high persistence alone a major cause of concern? Environ Sci Process Impacts 21:781-792

19. Nödler K, Scheurer M (2019) Substances from multiple sources (SMS): the presence of multiple primary and secondary sources of persistent and mobile organic contaminants is an upcoming challenge for the drinking water sector and regulatory frameworks. Environ Sci Technol 53:11061-11062

20. Schmidt CK, Brauch H-J (2008) N, N-dimethylsulfamide as precursor for $\mathrm{N}$-nitrosodimethylamine (NDMA) formation upon ozonation 
and its fate during drinking water treatment. Environ Sci Technol 42:6340-6346

21. European Parliament and Council (2000) Directive 2000/60/EC of the European Parliament and of the Council of 23 October 2000 establishing a framework for Community action in the field of water policy. Official Journal L 327, 22/12/2000 p. 1-73

22. Arp HPH, Brown TN, Berger U, Hale SE (2017) Ranking REACH registered neutral, ionizable and ionic organic chemicals based on their aquatic persistency and mobility. Environ Sci Process Impacts 19:939-955

23. Schulze S, Sättler D, Neumann M, Arp HPH, Reemtsma T, Berger U (2018) Using REACH registration data to rank the environmental emission potential of persistent and mobile organic chemicals. Sci Total Environ 625:1122-1128

24. Zahn D, Frömel T, Knepper TP (2016) Halogenated methanesulfonic acids: a new class of organic micropollutants in the water cycle. Water Res 101:292-299

25. Zahn D, Mucha P, Zilles V, Touffet A, Gallard H, Knepper TP, Frömel T (2019) Identification of potentially mobile and persistent transformation products of REACH-registered chemicals and their occurrence in surface waters. Water Res 150:86-96

26. Montes R, Aguirre J, Vidal X, Rodil R, Cela R, Quintana JB (2017) Screening for polar chemicals in water by trifunctional mixed-mode liquid chromatography-high resolution mass spectrometry. Environ Sci Technol 51:6250-6259
27. Schulze S, Zahn D, Montes R, Rodil R, Quintana JB, Knepper TP, Reemtsma T, Berger U (2019) Occurrence of emerging persistent and mobile organic contaminants in European water samples. Water Res 153:80-90

28. Richardson SD, Ternes TA (2018) Water analysis: emerging contaminants and current issues. Anal Chem 90:398-428

29. Bieber S, Greco G, Grosse S, Letzel T (2017) RPLC-HILIC and SFC with mass spectrometry: polarity-extended organic molecule screening in environmental (water) samples. Anal Chem 89:7907-7914

30. Berger U, Ost N, Sättler D, Schliebner I, Kühne R, Schüürmann G, Neumann M, Reemtsma T (2018) Assessment of persistence, mobility and toxicity (PMT) of 167 REACH registered substances. Texte 09/2018. Umweltbundesamt, Dessau-Roßlau. https://www.umweltbundesamt .de/sites/default/files/medien/1410/publikationen/2018-02-12_texte _09-2018_pmt-of-167-reach-substances_v3.pdf. Accessed 20 Dec 2019

31. Grummt T (2014) Regulatorisch-toxikologische Bewertung von 1,4-Dioxan (CAS-Nr. 123-91-1) im Trinkwasser. Answer of Umweltbundesamt to ARW Arbeitsgemeinschaft Rhein-Wasserwerke e.V. Bad Elster, Germany

\section{Publisher's Note}

Springer Nature remains neutral with regard to jurisdictional claims in published maps and institutional affiliations.

\section{Submit your manuscript to a SpringerOpen ${ }^{\odot}$ journal and benefit from:}

- Convenient online submission

- Rigorous peer review

- Open access: articles freely available online

- High visibility within the field

- Retaining the copyright to your article

Submit your next manuscript at $\boldsymbol{\text { springeropen.com }}$ 